\section{Hormonal status, creatine kinase and soccer: a need for research}

\author{
Perfil hormonal, creatinoquinase e futebol: necessidade de pesquisa
}

Anthony C. Hackney', Marco Machado²

S occer is a physically demanding sport in which muscular damage and trauma are frequent occurrences $(1,2)$. These occurrences are especially true for those athletes involved in top-division clubs at national or international levels. Many factors may come into play when determining the degree of muscular damage that may occur during a soccer match, such as intensity of physical participation, environmental conditions, skill level, prior level of rest, and aggressiveness of the teams involved in the match (2).

It is well-established that a multitude of hormones influence the degree of protein turnover in the human body. These hormones are typically categorized as anabolic (promoting protein synthesis) or catabolic (promoting protein degradation) in terms of their influence on protein turnover. Cellular protein turnover status can influence the structural integrity of a muscle, and thus its potential for damage (i.e., less integrity $\rightarrow$ greater risk of damage) (3). The disposition of anabolic and catabolic hormones to influence protein turnover and, in turn, their influence on the structural status of skeletal muscles, led us to speculate as to whether the basal hormonal status of an athlete before a soccer match would be a factor that potentially affects their muscle response to damage. To address this assumption, we conducted a preliminary study to examine the relationship between basal levels of anabolic-catabolic hormones and muscle damage, assessed by creatine kinase response following a 90 -minute soccer match. The study of muscular damage following sport activity is critical because of the influence such damage has on the adaptation and training responses of athletes and their ability to perform and compete in subsequent sport events $(1,3)$.

Twelve healthy male soccer players were recruited to participate in this study. All of them signed a written informed consent form before starting the study. These players were all experienced sportsmen and had participated in top-division soccer for a number of years (minimum 2 years as professionals). Their physical characteristics were as follows $($ mean $\pm \mathrm{SD})$ : age $=26.3 \pm 3.8$ yrs., height $=177.8 \pm 2.9 \mathrm{~cm}$, and body mass $=75.5 \pm 8.3 \mathrm{~kg}$.

Subjects rested and performed minimal physical activity in the 24 hours prior to the match. On the day of the match, basal, resting blood samples were collected from the subjects by venipuncture at $8 \mathrm{am}$ in the morning, after a 12-hour fast. Collected blood samples were handled using standard clinical procedures to ensure they were viable for later hormonal-hematological analysis. The soccer match took place in the afternoon of the day of blood sampling, at around $5 \mathrm{pm}$. The average temperature during the match was $27^{\circ} \mathrm{C}$. All 12 subjects participated in the 90 -minute match for equal amounts of time and were allowed to consume water ad libitum during the whole match. Immediately following the match, a post-match second blood sample
Applied Physiology Laboratory, Department of Exercise and Sport Science, University of North Carolina, Chapel Hill, NC, USA ${ }^{2}$ Laboratory of Physiology and Biokinetics, UNIG Campus $\checkmark$ at Itaperuna, RJ, Brazil

Correspondence to:

Laboratory of Human Movement Studies, Fundação Universitária de Itaperuna, Itaperuna, RJ, Brazil ach@email.unc.edu

Received on Feb/16/2012 Accepted on Apr/18/2012 
was withdrawn. For these athletes, the match represented the first competition of the season after a period of vacation and pre-season training ( 15 days).

Blood samples were analyzed for a selected profile of hormones and hematological measurements. In the basal resting specimens this consisted of: total $(t) \mathrm{T}_{3}$, free (f) $\mathrm{T}_{3}, \mathrm{tT}_{4}, \mathrm{fT}_{4}, \mathrm{TSH}, \mathrm{t}$-testosterone, f-testosterone, growth hormone, insulin, cortisol, creatine kinase $(\mathrm{CK})$, hematocrit, and hemoglobin. The post-match specimen measurements were: $\mathrm{CK}$, hematocrit, and hemoglobin. All biochemical analyses involved standard laboratory procedures.

Table 1 presents the hormonal-hematological responses of the subjects. All blood measurements were within clinically acceptable normal ranges. CK, hematocrit and hemoglobin were elevated in the post-match specimens $(\mathrm{CK}, \mathrm{p}<0.01$; hemoglobin, $\mathrm{p}<0.001$; hematocrit, $\mathrm{p}=0.059$ [t-test]). To assess the influence (relationship) of basal hormone levels in the magnitude of CK increase after the match, a multiple regression analysis was performed. The change in CK (delta value [X $\pm \mathrm{SE}] ; 137.8 \pm 44.2 \mathrm{U} / \mathrm{L}$ ) was used as the dependent variable, and basal hormonal concentrations as independent variables with a forward stepwise inclusion for the regression model $(\alpha<0.05)$. The following significant $(\mathrm{p}=0.02 \mathrm{l})$ regression model equation was found:

Table 1. Hormones and hematological responses of subjects

\begin{tabular}{lcc}
\hline Measurement & Mean & Standard error \\
\hline Pre-match & & \\
$\mathrm{tT}_{4}(\mu \mathrm{g} / \mathrm{dL})$ & 6.9 & 0.3 \\
$\mathrm{fT}_{4}(\mathrm{ng} / \mathrm{dL})$ & 0.95 & 0.03 \\
$\mathrm{tT}_{3}(\mathrm{ng} / \mathrm{dL})$ & 158.2 & 0.8 \\
$\mathrm{fT}_{3}(\mathrm{pg} / \mathrm{mL})$ & 3.8 & 0.1 \\
$\mathrm{TSH}(\mu \mathrm{Ul} / \mathrm{mL})$ & 2.46 & 0.38 \\
$\mathrm{t}$-Testosterone $(\mathrm{ng} / \mathrm{dL})$ & 944.1 & 78.3 \\
$\mathrm{f}-\mathrm{Testosterone}(\mathrm{pg} / \mathrm{mL})$ & 36.0 & 0.8 \\
Cortisol $(\mu \mathrm{g} / \mathrm{dL})$ & 22.6 & 0.8 \\
T-testosterone/Cortisol ratio & 44.0 & 5.4 \\
Growth hormone $(\mathrm{ng} / \mathrm{mL})$ & 0.3 & 0.1 \\
Insulin $(\mu \mathrm{U} / \mathrm{mL})$ & 5.6 & 0.3 \\
CK (U/L) & 695.0 & 128.3 \\
Hematocrit $(\%)$ & 45.6 & 0.9 \\
Hemoglobin $(\mathrm{g} / \mathrm{dL})$ & 15.2 & 0.4 \\
Post-match & & 163.5 \\
CK (U/L) & 832.8 & 0.4 \\
Hematocrit $(\%)$ & 46.8 & \\
Hemoglobin $(\mathrm{g} / \mathrm{dL})$ & 15.5 & \\
\hline
\end{tabular}

CK delta $=1789.7-33.1 \times($ f-testosterone $)-482.3$ $\mathrm{x}\left(\mathrm{fT}_{4}\right)$

This model indicates that the lower the basal f-testosterone and $\mathrm{fT}_{4}$ levels in the athletes, the greater the degree of CK elevation in response to the soccer match. This finding suggests that these athletes were experiencing greater degree of muscle damage during the match than those athletes with higher basal f-testosterone and $\mathrm{fT}_{4}$ levels. Such an interpretation would imply that having greater anabolic hormonal status could promote a more positive protein synthesis status, thus leading to a lesser an inclination towards muscle damage during a sport activity, such as soccer (i.e., this would be our a posteriori hypothesis from these findings). The anabolic actions of f-testosterone are well-established. But, $\mathrm{fT}_{4}$ also has such anabolic actions by both direct and indirect means; that is, via the conversion of $\mathrm{T}_{4}$ to $\mathrm{T}_{3}$ and this hormone's subsequent anabolic effects $(4,5)$. Interestingly, the latter hormone $\left(\mathrm{fT}_{3}\right)$ nearly reached significance to enter the regression model.

This preliminary study is limited in both scope and statistical strength of its findings. Nonetheless, the outcomes shed light on an area that, to our knowledge, has not been previously examined, and suggests the need for future research to address the hypothesis raised here. It would be interesting to develop studies in which the anabolic hormonal status is manipulated (i.e., by means of legal methods of nutritional supplementation; certainly not by means of drug doping) to robustly test the influence such a status has on muscle damage associated with sport activities.

Such research seems warranted, and an excellent pursuit for endocrinologists who study exercise and sport; this would seem especially pertinent with major sport events involving soccer in the near future, such as the 2012 Olympics (London), the 2014 FIFA World Cup (Brazil), and the rapidly approaching 2016 Olympics (Rio de Janeiro). Such major events always inspire young and old individuals alike to increase their participation in sport activities, which means sport medicine clinicians may have increased treatment opportunities for injuries and traumas in their practices. Well-conducted scientific research studies in the endocrinological aspects of exercise and sport may provide insights that perhaps could mitigate some of these injuries and traumas.

Disclosure: no potential conflict of interest relevant to this article was reported. 


\section{REFERENCES}

1. Ekblom B. Applied physiology of soccer. Sports Medicine. 1986;3(1):50-60.

2. Lazarim FL, Antunes-Neto JM, Silva FO, Nunes LA, Bassini-Cameron A, Cameron LC, et al. The upper values of plasma creatine kinase of professional soccer players during the Brazilian National Championship. J Sci Med Sport. 2009;12:85-90.
3. Morton JP, Kayani AC, McArdle A, Drust B. The exercise-induced stress response of skeletal muscle, with emphasis on humans. Sports Med. 2009;39(8):643-62.

4. Bates PC, Holder AT. The anabolic actions of growth hormone and thyroxine on protein metabolism in Snell dwarf and normal mice. J Endocrinol. 1988;119(1):31-41.

5. Huang BK, Golden LA, Tarjan G, Madison LD, Stern PH. Insulin-like growth factor I production is essential for anabolic effects of thyroid hormone in osteoblast. J Bone Miner Res. 2000;15:188-97. 